\title{
Synthesis and Characterization of a Water-Soluble Ionic Polyacetylene Derivative
}

\author{
Y.S. GAL ${ }^{a, *}$, S.H. JIN ${ }^{b}$, J. PARK ${ }^{c}$ AND K.T. LIM ${ }^{d}$ \\ ${ }^{a}$ Department of Fire Safety, Kyungil University, Gyeongsan 38428, Gyeongsangbuk-do, Korea \\ ${ }^{b}$ Department of Chemistry Education, Pusan National University, Busan 46279, Korea \\ ${ }^{c}$ Department of Chemistry, The Catholic University of Korea, Bucheon 14662, Korea \\ ${ }^{d}$ Department of Display Engineering, Pukyong National University, Busan 48513, Korea
}

\begin{abstract}
A new water-soluble ionic polyacetylene was synthesized by the acid-catalyzed polymerization of 2-ethynylpyridine using acrylic acid. The polymerization proceeded well to give a high yield of polymer. The acetylenic $\mathrm{C} \equiv \mathrm{C}$ bond stretching $\left(2110 \mathrm{~cm}^{-1}\right)$ and acetylenic $\equiv \mathrm{C}-\mathrm{H}$ bond stretching $\left(3293 \mathrm{~cm}^{-1}\right)$ peaks of 2-ethynylpyridine monomer were not seen in the FT-IR spectrum of polymer. The electro-optical and electrical properties of the ionic polyacetylene were measured and discussed. The resulting polymer showed strong maximum at $513 \mathrm{~nm}$ in the UV-Visible absorption, which is corresponding to photon energy of $2.42 \mathrm{eV}$. The energy gap width of polymer was estimated to be of $2.08 \mathrm{eV}$. It was observed that the electrochemical process of polymer is reproducible in the potential range of -1.80 to $1.60 \mathrm{~V}$ vs $\mathrm{Ag} / \mathrm{AgNO}_{3}$. $\mathrm{HOMO}$ and LUMO levels of polymer were $4.85 \mathrm{eV}$ and $2.77 \mathrm{eV}$, respectively.
\end{abstract}

DOI: 10.12693/APhysPolA.129.642

PACS/topics: 72.80.L, 73.61.P, 78.20.C, 78.30.J

\section{Introduction}

Conjugated organic polymers having a conjugated main chain are expected to show such unique properties as electrical and photo-conductivity [1-5], migration and transfer of energy [6], gas permeability [7, 8], optical nonlinearity $[9,10]$, electrochromism [11], solvatochromism [12], fluorescent sensitizing [13], and lightemission [14-18]. Thereby, these materials are important as the active materials in a new generation of electronic and optical devices, including light-emitting devices [15, 19-21], photovoltaic cells [22, 23], biological and chemical sensors [24, 25], photo-detectors [26], optical lasers [27], field-effect transistors [28], and nonvolatile memory devices $[29,30]$.

The main advantages of conjugated organic materials lie in their low cost and essentially their easy processability. The practical applications of polyacetylene (PA), the simplest conjugated polymer, have remained limited because PA itself is insoluble, infusible, and unstable to air oxidation although the electrical conductivity of PA can be controlled over the full range from insulator to metal through chemical doping $[1,31,32]$. Hence, the enormous work has been performed on the preparation and applications of various types of conjugated polymers such as PA derivatives, poly(fluorene)s, poly(phenylene vinylene)s, poly(p-phenylene)s, polythiophene and polyaniline derivatives $[3,7,33-37]$. Of these materials, the PA derivatives have been synthesized from the

\footnotetext{
*corresponding author; e-mail: ysgal@kiu.ac.kr
}

transition metal-catalyzed polymerization of the corresponding acetylenic monomers [33, 38-40].

The self-doped conducting polymers are defined as ionic conducting polymers which have the covalently bonded counterions. These materials show that the electrochemical oxidation of polymer main chain is accompanied by the ejection of cations. Various chemical classes of self-doped conjugated polymers have been described, together with their methods of synthesis, electrical conductivity, electro-optical and electrochemical properties, and potential applications [41, 42].

The spontaneous polymerization of ethynylpyridines using such appropriate compounds as bromine, methyl trifluoromethanesulfonate, and alkyl halides yielded a new type of conjugated polymers [43-45]. In a series of these works, we synthesized some ionic polyacetylenes via the spontaneous polymerization of monomeric ethynylpyridinium salts [46-48].

The pyridine-containing ionic PAs have been used as active materials for light-emitting devices [49], nanocomposite films via electrostatic layer-by-layer assembly [50], cationic poly(2-ethynylpyridinium chloride)silica nanohybrids [51], cyclodextrin-induced fluorescence enhancer [52], quaternized poly(pyridylacetylene)silver nanocomposites [53], and unipolar write-once-readmany-times (WORM) memory devices [54].

In this article, we prepared a new water-soluble ionic PA derivative with pyridyl moieties (Fig. 1) via the acid-catalyzed polymerization of 2-ethynylpyridine using acrylic acid. The electrical, electro-optical, and electrochemical properties of the resulting polymer were measured and discussed. 

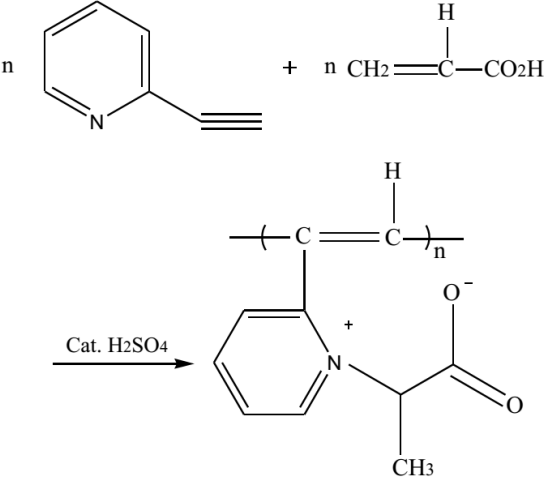

Fig. 1. Synthesis of PEPP.

\section{Experimental details}

\subsection{Materials}

Acrylic acid (Aldrich Chemicals., 99\%), 2-vinylpyridine (Aldrich Chemicals., 97\%), bromine (Aldrich Chemicals., 99.99+\%), and sodium amide (Aldrich Chemicals., 95\%) were reagent grade and used as received. Solvents were analytical grade materials. The bromination of 2-vinylpyridine and the consecutive dehydrobromination of 2-(tetrabromoethyl)pyridine were used for the synthesis of 2-ethynylpyridine according to the literature method [55]. 2-Ethynylpyridine was dried over $\mathrm{CaH}_{2}$ and distilled prior to use.

\subsection{Synthesis of Poly[2-ethynylpyridinium-(N-2-propionate)]}

Poly[2-ethynylpyridinium-(N-2-propionate)] (PEPP) was synthesized by the acid-catalyzed polymerization of 2-ethynylpyridine using acrylic acid as follows. 2-Ethynylpyridine (1.0 g, $9.7 \mathrm{mmol})$ and acrylic acid $(0.70 \mathrm{~g}, 9.7 \mathrm{mmol})$ were added in $\mathrm{N}, \mathrm{N}$ dimethylformamide (DMF, $7.0 \mathrm{~mL},[M]_{0}=1.0 \mathrm{M}$ ) at room temperature. After the reaction mixture was purged under nitrogen, the catalytic amount of sulfuric acid was injected and stirred at $80^{\circ} \mathrm{C}$. As the polymerization proceeded, the initial light-brown solution became into deep violets and the solution viscosity was increased. After reaction was completed, the reaction solution diluted with additional $10 \mathrm{~mL}$ DMF was precipitated into a large excess of ethyl ether. The precipitated polymer was filtered and the collected product was dried under vacuum at $40^{\circ} \mathrm{C}$. The black polymer powder was obtained in $72 \%$ yield.

\subsection{Characterization}

Fourier transform infrared spectroscopy (FT-IR) spectra were recorded using a Bruker EQUINOX 55 spectrometer using a $\mathrm{KBr}$ pellet. ${ }^{1} \mathrm{H}$ - and ${ }^{13} \mathrm{C}-\mathrm{NMR}$ spectra were recorded on a Varian $500 \mathrm{MHz}$ FT-NMR spectrometer (Model: Unity INOVA) in DMSO- $\mathrm{d}_{6}$ and chemical shifts are reported in ppm units with tetramethylsilane as an internal standard. The optical absorption spectra were measured using HP $8453 \mathrm{UV}$-visible spectrophotometer in DMF (concentration: ca $10^{-5} \mathrm{M}$ ). Photoluminescence spectra were obtained on a Perkin Elmer luminescence Spectrometer LS55 (Xenon flash tube) utilizing a lock-in amplifier system with a chopping frequency of $150 \mathrm{~Hz}$. Dilute solution viscosity measurements were made at $30^{\circ} \mathrm{C}$ using a Lauda viscometer at a concentration of $0.5 \mathrm{~g} / \mathrm{dL}$ in DMF. The electrical conductivity of the sample was determined by using a standard fourpoint probe measurement without extensive pumping of the doped pellets, with a Hewlett-Packard 3490 multimeter and a Keithley 616 Digital Electrometer. Conductivity was calculated from the measured resistance of the sample [2]. Electrochemical measurements were carried out with WBCS 3000 system. To examine electrochemical properties, the polymer solution was prepared and the electrochemical measurements were performed under $0.1 \mathrm{M}$ tetrabutylammonium perchlorate (TBAP) solution containing DMF. ITO, $\mathrm{Ag} / \mathrm{AgNO}_{3}$ and platinum wire were used as a working, reference and counter electrode, respectively.

\section{Results and discussion}

To date, the water-soluble ionic conducting polymers have been prepared via the polymeric reaction of precursor polymers [41, 42]. Here, a new ionic conjugated polymer was synthesized by the acid-catalyzed polymerization of 2-ethynylpyridine using acrylic acid. In the cases using such activating compounds as bromine, iodine, and alkyl halides, the polymerization of 2-ethynylpyridine proceeded spontaneously without any additional initiator or catalyst. However, the present polymerization of 2ethynylpyridine using acrylic acid did not nearly proceed at $60^{\circ} \mathrm{C}$. This means that the present system does not have the activated 2-ethynylpyridinium salts in the simple mixing of 2-ethynylpyridine and acrylic acid. Thus, we used the catalytic amount of sulfuric acid to activate the polymerization of 2-ethynylpyridine using acrylic acid. As a result, the polymerization proceeded well in homogeneous state. As the reaction time passed, the reaction mixture became more viscous and the color of reaction mixture was changed from the light brown of the initial mixture into deep violets. The resulting precipitants were filtered and dried to give the black polymer powder in $72 \%$ yield.

The resulting PEPP shows somewhat hygroscopic property. Such ionic conjugated polymers as poly(2ethynylpyridinium tosylate) and poly(2-ethynyl-Nmethylpyridinium iodide) showed similar hygroscopic property [56, 57], whereas the ionic conjugated polymers with simple alkyl substituents exhibited non-hygroscopic property [46, 47]. This polymer was completely soluble in such polar solvents as water, pyridine, DMF, DMSO, and NMP. The inherent viscosity of PEPP was $0.15 \mathrm{dL} / \mathrm{g}$. This value is similar with those of ionic polyacetylenes such as poly(2-ethynyl-Npropargylpyridinium bromide) [46] and poly[2-ethynyl$\mathrm{N}$-(propanesulfonate)pyridinium betaine] [58]. 
Such analytical methods as FT-NMR, FT-IR, and UVvisible spectroscopies were used for the characterization of polymer molecular structure. The ${ }^{1} \mathrm{H}-\mathrm{NMR}$ spectrum of PEPP (measured in DMSO- $\mathrm{d}_{6}$ ) showed the aromatic protons of the pyridyl and the vinyl protons of conjugated polymer backbone at 5.8-10.1 ppm. The methyl and methine proton peaks of $\mathrm{N}-2$-propionate groups were observed in the range of $3.7-5.3 \mathrm{ppm}$. The ${ }^{13} \mathrm{C}-\mathrm{NMR}$ spectrum of PEPP showed the aromatic carbon peaks of pyridyl moieties and the vinyl carbon peaks of conjugated polymer backbone in range of $110-160 \mathrm{ppm}$. The methine carbon peaks adjacent to the carboxylate groups are also observed at $79 \mathrm{ppm}$, whereas the carbonyl carbon peaks of N-2-propionate groups was seen at $162 \mathrm{ppm}$.

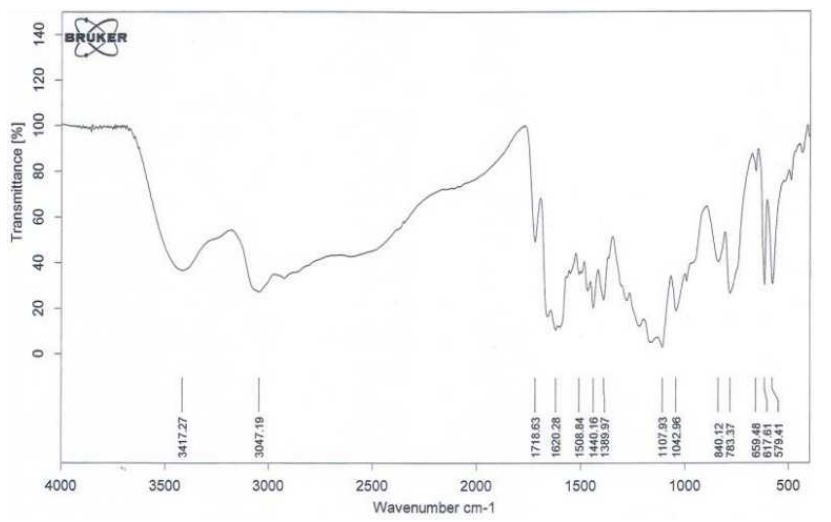

Fig. 2. FT-IR spectrum of PEPP in $\mathrm{KBr}$ pellet.

The FT-IR spectrum of PEPP is shown in Fig. 2. In the FT-IR spectrum of 2-ethynylpyridine itself, the specific acetylenic $\mathrm{C} \equiv \mathrm{C}$ bond stretching $\left(2110 \mathrm{~cm}^{-1}\right)$ and acetylenic $\equiv \mathrm{C}-\mathrm{H}$ bond stretching $\left(3293 \mathrm{~cm}^{-1}\right)$ peaks had been seen. However, this FT-IR spectrum of PEPP did not show the characteristic acetylenic peaks. Instead, the $\mathrm{C}=\mathrm{C}$ stretching frequency peak of conjugated polymer backbone around $1620 \mathrm{~cm}^{-1}$ became more intense in comparison with those of the $\mathrm{C}=\mathrm{C}$ and $\mathrm{C}=\mathrm{N}$ stretching frequencies of 2-ethynylpyridine. The vinylic $=\mathrm{C}-$ $\mathrm{H}$ stretching frequency of polymer main chain was observed at $3047 \mathrm{~cm}^{-1}$. The strong peak at $1107 \mathrm{~cm}^{-1}$ is due to the symmetric $\mathrm{C}-\mathrm{O}-\mathrm{C}$ stretching frequency of N-2-propionate group, whereas the carbonyl carbon peaks are observed at $1718 \mathrm{~cm}^{-1}$. The broad peak at around $3417 \mathrm{~cm}^{-1}$ may be originated from the $=\mathrm{N}-\mathrm{H}$ stretching of pyridinium rings and/or the absorbed moisture. The optical absorption spectrum of PEPP showed that the absorption spectrum starts around $610 \mathrm{~nm}$ and shows a strong absorption band at a visible region, which is due to the $\pi \rightarrow \pi^{*}$ transition associated with the conjugated polymer backbone. From these spectral data, it was concluded that PEPP has the conjugated polymer backbone system bearing the ionic pyridyl substituents with N-propionate group.

Although PEPP is one of self-doping type polymers [42], the as-prepared polymer exhibits relatively low electrical conductivity $\left(<10^{-7} \mathrm{~S} / \mathrm{cm}\right)$, consisted with neutral polyacetylene derivatives $[47,58]$. The electrical conductivity of conjugated polymer was increased significantly through the oxidation of the polymers with conventional oxidants. PEPP polymer pellet subjected to vapor-phase iodine showed large, irreversible iodine uptakes with no significant decrease in iodine content even after prolonged vacuum pumping ( $6 \mathrm{hrs}$ ). The electrical conductivity of iodine-doped PEPP pellet [sample composition: $\left.(\mathrm{PEPP})_{1}\left(\mathrm{I}_{2}\right)_{0.30}\right]$ was $1.41 \times 10^{-2} \mathrm{~S} / \mathrm{cm}$. This means that the auto-doped materials can be further oxidized with oxidizing agents to increase their conductivity by an order of magnitude. In other work, poly $[\omega-$ (3-thienyl)alkanesulfonates] with the sulfonic acid form are self-doped and exhibited electrical conductivities of $5 \times 10^{-2}-10^{-1} \mathrm{~S} / \mathrm{cm}[59]$.

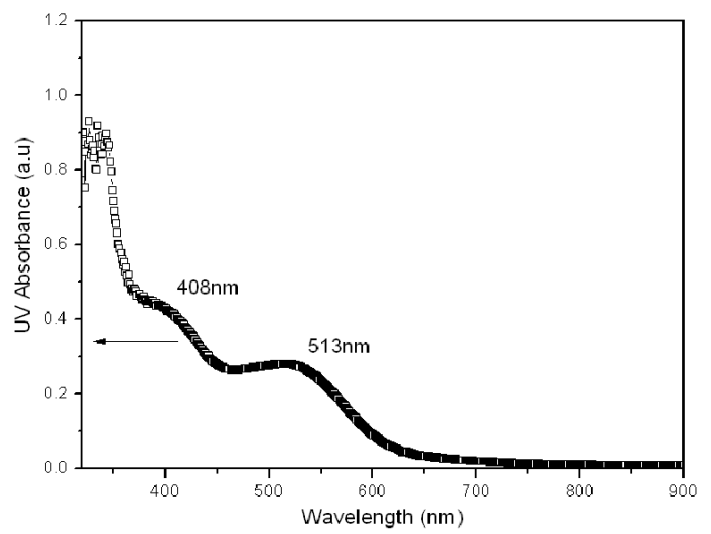

Fig. 3. Optical absorption spectrum of PEPP in DMF solution $\left(2.26 \times 10^{-5} \mathrm{M}\right)$.

Figure 3 shows the UV-visible spectrum for PEPP solution $\left(2.26 \times 10^{-5} \mathrm{M}, \mathrm{DMF}\right)$. PEPP showed strong maximum at $513 \mathrm{~nm}$ which is corresponding to photon energy of $2.42 \mathrm{eV}$. The energy gap width of PEPP was estimated to be of $2.08 \mathrm{eV}$ from an analysis of the absorption edge using a plot of $(h \nu)$ versus $(\alpha h \nu)^{2}$, where $\alpha, h$, and $\nu$ are the absorbance, Planck's constant, and the frequency of light, respectively [60].

To evaluate the electrochemical property of PEPP for electro-active application, cyclic voltammetry (CV) was measured with the consecutive 30 scans. As shown in Fig. 4, we performed the CVs of PEPP solution with scan rate of $100 \mathrm{mV} / \mathrm{s}$ to determine the oxidation and reduction property of $\mathrm{PEPP}$. It was observed that PEPP shows very stable cyclic voltammograms from the consecutive scans of more than 30 cycles. This result suggests that the electrochemical process of PEPP is reproducible in the potential range of -1.80 to $1.60 \mathrm{~V}$ vs $\mathrm{Ag} / \mathrm{AgNO}_{3}[47,48]$. Additionally, the oxidation of PEPP was started at $0.03 \mathrm{~V}$, where the vinylene unit of the conjugated polymer backbone could be oxidized in the scan and the redox process was irreversible. Based on ferrocene reference calibration, HOMO level of PEPP was $4.85 \mathrm{eV}$ and LUMO level was $2.77 \mathrm{eV}$. 


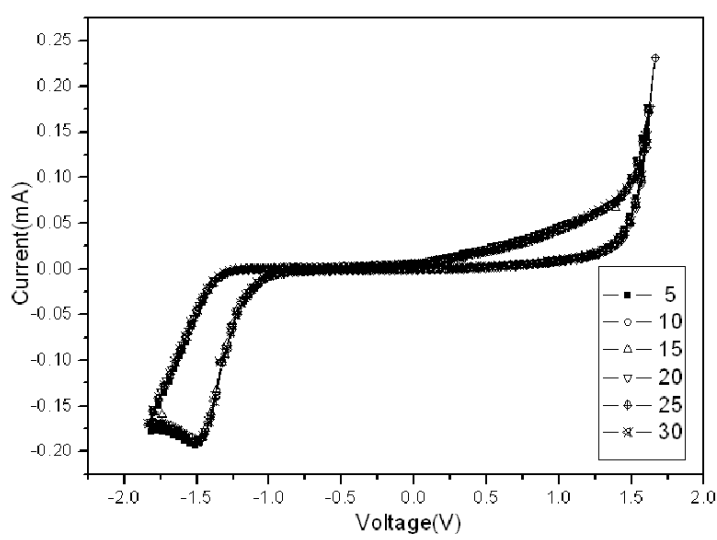

Fig. 4. Cyclic voltammograms of PEPP $[0.1 \mathrm{M}$ (n$\left.\mathrm{Bu})_{4} \mathrm{NBF}_{4} / \mathrm{DMF}\right]$ with consecutive scans under $100 \mathrm{mV} / \mathrm{sec}$.

\section{Conclusions}

A new water-soluble ionic polyacetylene was synthesized by the acid-catalyzed polymerization of 2ethynylpyridine using acrylic acid. A small amount of sulfuric acid activated the polymerization of 2ethynylpyridine. The polymerization proceeded well in homogeneous manner to give a high yield of polymer. The resulting black polymer was mostly soluble in such solvents as water, pyridine, DMF, DMSO, and NMP and the inherent viscosity of resulting polymer was $0.15 \mathrm{dL} / \mathrm{g}$. FT-IR spectrum of PEPP did not show the acetylenic $\mathrm{C} \equiv \mathrm{C}$ bond stretching $\left(2110 \mathrm{~cm}^{-1}\right)$ and acetylenic $\equiv \mathrm{C}-\mathrm{H}$ bond stretching $\left(3293 \mathrm{~cm}^{-1}\right)$ frequencies of 2-ethynylpyridine. The electrical conductivity of iodine-doped PEPP was $1.41 \times 10^{-2} \mathrm{~S} / \mathrm{cm}$. The UV-visible spectrum of PEPP showed strong maximum at $513 \mathrm{~nm}$ which is corresponding to photon energy of $2.42 \mathrm{eV}$. The energy gap width of PEPP was estimated to be of $2.08 \mathrm{eV}$. It was observed that the electrochemical process of PEPP is reproducible in the potential range of -1.80 to $1.60 \mathrm{~V}$ vs $\mathrm{Ag} / \mathrm{AgNO}_{3}$.

\section{Acknowledgments}

This work was supported by grant fund from the National Research Foundation (NRF) (2011-0028320) by the Ministry of Science, ICT \& Future Planning (MSIP) of Korea.

\section{References}

[1] C.K. Chiang, C.R. Fincher, Y.W. Park, A.J. Heeger, H. Shirakawa, E.J. Louis, S.C. Gau, A.G. MacDiarmid, Phys. Rev. Lett. 39, 1098 (1977).

[2] Y.S. Gal, S.K. Choi, J. Appl. Polym. Sci. 50, 601 (1993).

[3] J.W. Park, J.H. Lee, H.N. Cho, S.K. Choi, Macromolecules 26, 1191 (1993)

[4] K. Yoshino, K. Yoshiimoto, S. Morita, T. Kawai, S.H. Kim, K.L. Kang, S.K. Choi, Syn. Met. 69, 81 (1995).
[5] N.D. Gupta, S. Maity, K.K. Chattopadhyay, J. Ind. Eng. Chem. 20, 3208 (2014).

[6] I. Hwang, G.D. Scholes, Chem. Mater. 23, 610 (2011).

[7] T. Masuda, E. Isobe, T. Higashimura, K. Tanaka, J. Am. Chem. Soc. 105, 7473 (1983).

[8] T. Aoki, T. Fukuda, K.-I. Shinohara, T. Kaneko, M. Teraguchi, M. Yagi, J. Polym. Sci. A: Polym Chem. 42, 4502 (2004).

[9] H.J. Lee, J.M. Oh, S.J. Choi, H.K. Kim, S.K. Choi, Polym. Bull. 32, 433 (1994).

[10] H.J. Lee, Y.H. Won, S.J. Kang, S.K. Choi, H.K. Kim, J. Polym. Sci. A: Polym. Chem. 34, 2333 (1996).

[11] G. Dufresne, J. Bouchard, M. Belletete, G. Durocher, M. Leclerc, Macromolecules 33, 8252 (2000).

[12] J. Chen, Z. Xie, J.W.Y. Lam, C.C.W. Law, B.Z. Tang, Macromolecules 36, 1108 (2003).

[13] C. Zhou, Y. Gao, D. Chen, J. Phys. Chem. B 116 , 11552 (2012).

[14] K. Tada, R. Hidayat, M. Teraguchi, T. Masuda, K. Yoshino, Jpn. J. Appl. Phys. 35, L1138 (1996).

[15] S.J. Jung, Y.R. Cho, S.H. Jin, S.C. Kim, W.S. Shin, J.W. Lee, Y.S. Gal, Curr. Appl. Phys. 7, 375 (2007).

[16] M.S. AlSalhi, J. Alam, L.A. Dass, M. Raja, Int. J. Mol. Sci. 12, 2036 (2011).

[17] Y.S. Gal, S.H. Jin, Y. Park, J. Park, K.T. Lim, S.Y. Kim, J. Nanosci. Nanotech. 14, 5480 (2014).

[18] Y.S. Gal, S.H. Jin, J.W. Park, K.T. Lim, J. Ind Eng. Chem. 30, 261 (2015).

[19] J.H. Burroughes, D.D.C. Bradley, A.R. Brown, R.N. Marks, K. Mackay, R.H. Friend, P.L. Burns, A.B. Holmes, Nature 347, 539 (1990).

[20] S.H. Jin, M.Y. Kim, J.Y. Kim, K. Lee, Y.S. Gal, J. Am. Chem. Soc. 126, 2474 (2004).

[21] C.W. Lee, O.Y. Kim, J.Y. Lee, J. Ind. Eng. Chem. 20, 1198 (2014).

[22] W. Cho, J.W. Lee, Y.S. Gal, M.R. Kim, S.H. Jin, Mater. Chem. Phys. 143, 904 (2014).

[23] S.H. Jin, H. Yoo, C. Lee, C. Saravanan, Y.S. Gal, J.W. Lee, Mol. Cryst. Liq. Cryst. 597, 135 (2014).

[24] D.T. McQuade, A.E. Pullen, T.M. Swager, Chem. Rev. 100, 2537 (2000).

[25] D. Ragupathy, S.C. Lee, S.S. Al-Deyab, A. Rajendren, J. Ind. Eng. Chem. 20, 930 (2014).

[26] X. Duan, L. Liu, F. Feng, S. Wang, Acc. Chem. Res. 43, $260(2010)$.

[27] M.D. McGehee, A.J. Heeger, Adv. Mater. 12, 1655 (2000).

[28] J. Zaumseil, H. Sirringhaus, Chem. Rev. 107, 1296 (2007).

[29] T.J. Lee, S. Park, S.G. Hahm, D.M. Kim, K. Kim, J. Kim, W. Kwon, Y. Kim, T. Chang, M. Ree, J. Phys. Chem. C. 113, 3855 (2009).

[30] P. Heremans, G.H. Gelinck, R. Muller, K.J. Baeg, D.Y. Kim, Y.Y. Noh, Chem. Mater. 23, 341 (2011).

[31] A.J. Heeger, Angew. Chem. Int. Ed. 40, 2591 (2001).

[32] Y.W. Park, Chem. Soc. Rev. 39, 2428 (2010). 
[33] J.W.Y. Lam, B.Z. Tang, J. Polym. Sci. A: Polym. Chem. 41, 2607 (2003).

[34] S.H. Jin, H.J. Park, J.Y. Kim, K. Lee, S.P. Lee, D.K. Moon, H.J. Lee, Y.S. Gal, Macromolecules 35, 7532 (2002).

[35] X. Wang, P. Liu, J. Ind. Eng. Chem. 20, 1324 (2014).

[36] V. Chaudhary, A. Kaur, J. Ind. Eng. Chem. 26, 143 (2015).

[37] M.N.F. Razali, A.W. Mohammad, N. Hilal, J. Ind. Eng. Chem. 20, 3134 (2014).

[38] S.K. Choi, Y.S. Gal, S.H. Jin, H.K. Kim, Chem. Rev 100, 1645 (2000).

[39] Y.S. Gal, S.H. Jin, S.K. Choi, J. Mol. Cat. A: Chem. 213, 115 (2004).

[40] E.H. Kang, I.S. Lee, T.L. Choi, J. Am. Chem. Soc. 133, 11904 (2011).

[41] N. Zhang, R. Wu, Q. Li, K. Pakbaz, C.O. Yoon, F. Wudl, Chem. Mater. 5, 1598 (1993).

[42] M.S. Freund, B. Deore, Self-Doped Conducting Polymers, John Wiley \& Sons, Chichester, UK 2007.

[43] S. Subramanyam, A. Blumstein, Macromolecules 24, 2668 (1991)

[44] H. Okawa, K. Kurosawa, T. Wada, H. Sasabe, Syn. Met. 71, 1657 (1995).

[45] A. Blumstein, L. Samuelson, Adv. Mater. 10, 173 (1998).

[46] Y.S. Gal, W.C. Lee, S.Y. Kim, J.W. Park, S.H. Jin, K.N. Koh, S.H. Kim, J. Polym, Sci. A: Polym. Chem. 39, 3151 (2001).

[47] Y.S. Gal, S.H. Jin, J.W. Park, J. Polym, Sci. A Polym. Chem. 45, 5679 (2007).
[48] Y.S. Gal, S.H. Jin, K.T. Lim, J.W. Park, J. Nanosci. Nanotech. 15, 1842 (2015).

[49] A.J. Epstein, Y.Z. Wang, S.W. Jessen, J.W. Blatchford, D.D. Gebler, L.B. Lin, T.L. Gustafson, T.M. Swager, A.G. MacDiarmid, Macromol. Sym. 116, 27 (1997)

[50] H. Liu, D.W. Kim, A. Blumstein, J. Kumar, S.K. Tripathy, Chem. Mater. 13, 2756 (2001).

[51] T. Ogoshi, Y. Chujo, Macromolecules 38, 9110 (2005).

[52] K.M. Kim, J.H. Lim, N.Y. Jang, S.R. Kim, Macromol. Symp. 249-250, 562 (2007).

[53] O. Dammer, B. Vlckova, M. Prochazka, J. Sedlacek, J. Vohlidal, J. Pfleger, Phys. Chem. Chem. Phys. 11, 5455 (2009).

[54] Y.G. Ko, W. Kwon, D.M. Kim, K. Kim, Y.S. Gal, M. Ree, Polym. Chem. 3, 2028 (2012).

[55] Y.S. Gal, S.H. Jin, J.W. Park, K.T. Lim, S.Y. Kim Mol. Cryst. Liq. Cryst. 618, 21 (2015).

[56] Y.S. Gal, W.C. Lee, S.J. Lee, J.W. Park, J.M. Ko, J.H. Chun, J. Macromol. Sci.-Pure Appl. Chem. A36, 1503 (1999).

[57] Y.S. Gal, S.H. Jin, Macromol. Symp. 328, 20 (2013).

[58] Y.S. Gal, S.H. Jin, J.W. Park, K.T. Lim, Syn. Met. 174, 19 (2013).

[59] M.I. Arroyo, G. Diaz-Quijada, M.S.A. Abdou, S. Holdcroft, Macromolecules 28, 975 (1995).

[60] T.L. Gui, S.H. Jin, J.W. Park, K. Koh, S.H. Kim, K.T. Lim, Y.S. Gal, Mol. Cryst. Liq. Cryst. $\mathbf{4 2 5}$ 237 (2004). 